M. M. T. Hendrikx

L. W. A. van der Schot

F. M. E. Slijper

J. Huisman

A. F. Kalverboer

\title{
Phenylketonuria and some aspects of emotional development
}

\author{
Abstract Early dietary treatment of \\ phenylketonuria (PKU) prevents in- \\ tellectual retardation and gross neu- \\ rological impairment although not all \\ neuropsychological problems. This \\ study investigates to what extent the \\ illness and its treatment imposes a \\ burden on emotional development of \\ early-treated PKU patients and on \\ rearing practices of their parents. It \\ is concluded that in early-treated \\ PKU it is particularly difficult to find \\ constructive ways to adapt to the sit- \\ uation for children as well as for par- \\ ents. As coping with PKU and its \\ treatment is so complicated, paedi- \\ atric control should be combined \\ with psychocounselling.
}

Key words Phenylketonuria Diabetes mellitus - Emotional aspects - Treatment
Abbreviations $C B C L-p$ child behaviour check list, parents form $D M$ diabetes mellitus - $D Q C$ depression questionnaire for children EvIl evaluation of illness $\cdot H Y P-p$ hyperactivity score on CBCL-p IMP impulsivity score on MFFT - IN inadequacy score on DPQ-C (self- esteem) $\cdot P K U$ phenylketonuria Restr restrictiveness score on CRPR - SI social inadequacy score on DPQ-C

\section{J. Huisman}

Department of Medical Psychology, Free University Hospital, Amsterdam, The Netherlands

A. F. Kalverboer

Laboratory for Experimental Clinical Psychology, State University Groningen, The Netherlands

\section{Introduction}

Early treatment of phenylketonuria (PKU) is highly effective in preserving general intellectual abilities $[6,11,19]$ but many authors have reported neuropsychological/cognitive dysfunction $[5,8,9,12,14-16,20]$. Little is known about effects of treatment on personality development. Aspects of family functioning and emotional development secondary to treatment may add to the problems [2]. Changes that start as integrated responses to diet adherence may end up as rigid routines [13]. Tensions may run high. Small children cry when blood is taken and levels of phenylalanine (phe) are often awaited with great anxiety, fear of mental retardation always being present. One relevant observation in our group is that many patients learn to control their diet at a remarkably young age. From 4 or even 3 years onward most of them are able to refuse food offered to them by kind but unaware people. This precocious selfcontrol is obviously adaptive from a dietary point of view but we doubt whether the same is true in a psychological sense.

The aim of this study was to explore some aspects of behavioural and emotional development in early-treated children with PKU and of rearing practices of their parents. To discriminate between neuropsychological/cognitive and emotional dysfunction we first investigated impulsivity as a cognitive style, expecting children with PKU 
to be more impulsive then non-PKU children. Secondly, we investigated rearing styles of parents, expecting parents of PKU children to exert stricter rearing practices than parents of non-PKU children. Thirdly, we questioned parents on their perceptions of their children, expecting parents of children with PKU to perceive their children as more hyperactive, less socially competent and as having more behaviour problems than other parents. Fourthly, we asked the children about their own views on their illness and lastly we asked the children about depressive feelings and feelings of selfesteem, expecting children with PKU to be more depressed and have lower selfesteem then healthy children. Because of the possibility that effects of chronic illness have a general nature and are not PKUspecific we also investigated children with diabetes mellitus (DM).

\section{Patients and methods}

Patients

We invited all early-treated PKU patients and their parents in four academic hospitals who were between 9 and 13 years of age. We also invited all DM patients in our hospitals that were diagnosed before the age of 4 years and were of the same age as our PKU group. Of the invited families, $64 \%$ and $58 \%$ respectively participated. We interviewed all non-participants. Non-participation depended on practical circumstances such as summer vacation and distance in all cases. The PKU group consisted of 12 girls and 10 boys $(n=22)$. The DM group consisted of 8 girls and 6 boys $(n=$ 14 ). In the PKU group mean I.Q. is 92.09 (WISC-R dutch validation). In the DM group I.Q.'s were lacking. However, all children attend normal schools. Normgroups are mentioned below under measures.

\section{Measures}

Impulsivity as a cognitive style of problem solving characterized by poor inhibition (an indication of neuropsychological dysfunction) was measured with the widely used matching familiar figures test [7]. Testscores of 77 healthy dutch children of the same age range were used as norms.

Restrictiveness as a generalized rearing style was measured by the child rearing practices report which was developed by Block and Block [3] and adapted to the dutch situation by Dekovic [4] whose control children were used as normgroup. From this questionnaire we also used the nurturance scale (nurt, expression of warmth, acceptance, understanding). Hyperactivity, social competence and behaviour problems as perceived by parents is measured by the child behaviour check list-parents form (CBCL) as developed by Achenbach [1] and adapted to the dutch situation by Verhulst et al. [18] who also assessed norms for the dutch population.

Evaluation of illness (EvIl) by children with either PKU or DM was investigated with a self-report questionnaire we developed for this study. The EvIl consists of 23 items on a 4-point scale (neversometimes-often-always). The content of the items describes thoughts and feelings about either PKU or DM (parallel forms) such as "If you have PKU you are never-sometimes-often-always unhappy" or "If one has PKU one has never-sometimes-often-always difficulties in life" or "When I was little and blood was taken I never-sometimes-often-always had to cry". Thus items ask the child to estimate the severity of consequences of the illness for daily, social and future life.

Depression was assessed by the depression questionnaire for children (DQC) which has dutch norms [21].

Selfesteem (IN) was measured with the dutch personality questionnaire for children, inadequacy-scale (IN, vague physical complaints, depressed mood, vague fears and feelings of insufficiency). From this self-report questionnaire we also used the social inadequacy-scale (SI, avoidance of and feeling unhappy in social contacts). These scales have dutch norms [10].

\section{Statistics}

We used $t$-tests for differences in means, one-tailed for all data. To measure the strength of relationships between variables we computed product moment correlation coefficients.

\section{Results}

$T$-test results on all variables but EvIl (because of unavailability of norms, see below) are presented in Table 1 . Within the PKU group results are significant on impulsivity as a cognitive style, restrictiveness and nurturance as rearing styles, hyperactivity and social competence according to parents, and selfesteem. The DM group differed from population norms only on social competence according to parents. Direct comparison of PKU and DM groups (no table, data available on request) revealed significant differences on nurturance $(P 0.001)$ and on evaluation of illness $(P 0.01)$, although some other differences
Table $1 T$-tests for significance of mean differences. Impulsivity (IMP), restrictiveness (Restr), nurturance (Nurt), hyperactivity according to parents (Hyp-p), social competence according to parents (SC-p), behavior problems according to parents (BP-p), depression (DQC), selfesteem (IN) and social inadequacy (SI) between PKU and normgroup and between DM and normgroup

$* P<0.01 ; * * P<.001$

\begin{tabular}{lrrrrrrr}
\hline & Norm & $\begin{array}{l}\text { PKU } \\
\text { mean }\end{array}$ & SD & $t$-value & $\begin{array}{l}\text { DM } \\
\text { mean }\end{array}$ & SD & $t$-value \\
\hline IMP & -0.19 & 0.65 & 1.22 & $2.36^{*}$ & -0.09 & 1.68 & 0.18 \\
Restr & 2.97 & 3.49 & 0.80 & $3.02^{*}$ & 3.10 & 0.84 & 0.53 \\
Nurt & 5.18 & 5.45 & 0.36 & $3.49^{* *}$ & 4.88 & 0.50 & -2.17 \\
Hyp-p & 2.96 & 6.36 & 5.25 & $3.03^{*}$ & 4.36 & 3.56 & 1.52 \\
SC-p & 20.36 & 16.73 & 3.89 & $-4.40^{* *}$ & 16.36 & 3.79 & $-4.03^{* *}$ \\
BP-p & 19.97 & 24.09 & 14.68 & 1.32 & 26.50 & 19.57 & 1.33 \\
DQC & 21.00 & 21.59 & 13.71 & 0.06 & 18.00 & 9.32 & -0.93 \\
IN & 14.48 & 19.64 & 8.53 & $2.77^{*}$ & 17.07 & 7.62 & 1.22 \\
SI & 11.40 & 11.73 & 5.14 & 0.30 & 11.29 & 5.22 & -0.08 \\
\hline
\end{tabular}


Fig.1 Significant correlations within the PKU group

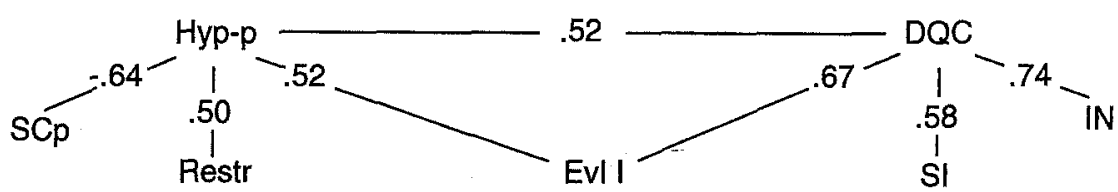

approached significance (IMP $P$ 0.08, Restr $P$ 0.10, Hyp-p $P$ 0.09). Figure 1 presents a hypothetical clustering of all significant correlations found between variables within the PKU group. There were no significant correlations between I.Q. and any of the variables (data available on request).

\section{Discussion}

Our questions concerned primarily emotional problems secondary to the nature and treatment of PKU. Interactions between emotional and neuropsychological factors may be ongoing but they may also be independent. The concept of impulsivity for instance has more than one meaning. One is a cognitive style, a concept that is easily associated with supposed neuro(psycho)logical impairment. A second meaning of impulsivity is uncontrolled behaviour, i.e. inability to delay gratification [17], restlessness, hyperkinesia. In hyperactivity according to DSM III-R criteria (diagnostic and statistical manual of mental disorders) both types of inhibition problems - as they are usually seen - are present. The "uncontrolled behaviour" type of impulsivity leads to troublesome behaviour that is hard to rule for parents though not necessarily antisocial or even disobedient. This is in fact what was found in the Smith et al. [14] study using the Rutter behaviour questionnaire (schoolteachers report). Here "hyperactivity" is described as "fidgety, restless and cannot settle". In our study we found high scores on "impulsivity" as a cognitive style as well as on "hyperactivity" (parents report on behaviour) in PKU patients. However we did not find a relation between these two ( $r 0.13)$ nor between "impulsivity" and any of the other behavioural/emotional variables. This strengthens our belief that in early-treated PKU, possible brain damage resulting in neuropsycholog$\mathrm{ical} /$ cognitive dysfunctioning - as in "impulsivity" - may be present independent of emotional/behavioural difficulties stemming from an illness and its treatment that are inherently stressfull. To study this hypothesis in more detail Phe levels should be included and multivariate analysis carried out (requiring a greater number of subjects). We found low selfesteem in PKU children (Table 1). According to their parents they were more "hyperactive" and less socially competent than healthy children. These parents exerted more restrictive as well as more nurturant rearing practices than parents of healthy children. Compared to DM children some of the differences remained (see results). Moreover evaluation of illness was significantly more negative in PKU children than in DM children. Our expectation that PKU children (and their parents) suffer and that this suffering is in some ways specific to earlytreated PKU was confirmed. There are several possible explanations. One is indicated by the correlation found (in PKU not in DM) between Hyp-p and Restr. We might perhaps theorize that when parents of early-treated PKU patients perceive their childs behaviour as "uncontrolled" (see above) - whether this is a correct perception or not they may respond by being more restrictive, presumably to restore a desired level of control. This rearing style may be a generalization of necessary dietary control. The Shulman et al. [13] study found parental perception - of child depression in their case - to be of influence on their functioning as a parent. The result on restrictiveness may be in line with this. An alternative more comprehensive explanation is illustrated by the clustering of significant relations in Fig. 1: the left side of Fig. 1 contains parental perceptions of child behaviour and restrictive rearing style. The right side contains feelings of the children. In PKU paediatricians strongly instruct parents to supervise their childs diet. There is no direct physical feedback of noncompliance, only fear of irreversible mental retardation. This way parents are made fully responsible for their childs physical and mental development. Awiszus and Unger [2] found PKU parents to be in conflict between striving for ideal Phe levels and striving for a healthy personality development of their child. According to our data PKU parents were both restrictive and nurturant. Normally these rearing styles are negatively related (as they were in DM parents $r-0.66)$. In PKU parents they were not $(r-0.00)$, possibly reflecting inner conflict. In DM paediatricians stimulate patients from a relatively young age onward to selfcontrol of their treatment (dieting and injections) thus partly taking it out of parents' hands. Noncompliance leads to direct physical feedback and consequences are usually reversible. Perhaps paediatricians (different instructions) and parents (different rearing styles) and children (different evaluation of illness) all feel differently about PKU and DM respectively. Each party in this triangle may have (unconsciously perhaps) slightly different priorities depending on position and responsibilities.

The correlations in Fig. 1 between IN, SI and DQC (depression) are probably due to overlap as IN and SI concern depressive feelings about specific parts of mental life (selfesteem and social inadequacy). The relation between DQC and Hyp-p (contradictory as depression usually relates to lack of activity) is confounded by EvIl (adjusted $r$ 0.27), leaving EvIl to be the stronger connection between the parent and child cluster. More research needs to be 
done on the relationship between parental rearing styles and perceptions of the child and their childrens' selfperceptions.

Both PKU and DM parents considered their child-patient as less socially competent than healthy children. Social competence on the CBCL concerns degree of social participation, in clubs, with friends or with other people. It is probably true that chronic patients are generally more withdrawn than healthy people. Neither group classified their children as having behaviour problems. As behaviour problems on the CBCL are well known behaviour and/or emotional problems with a fairly high prevalence (at least 5\%) in the general population; this means that parents in our groups did not see their child as having any psychopathological problems. PKU parents found their children hyperactive and difficult to restrict and socially less competent and more in need of nurturance than DM parents but they did not find them "ill-willed" or "emotionally disturbed". Smith et al. [14] advocated stricter Phe control. The British PKU patients in cohort 2 of the extensive Smith study were born between 1972 and 1977 and received treatment before 4 months of age. Our patients, born between 1981 and 1985, were all treated before 20 days of age. Control of Phe levels has been very frequent. It may be difficult to further improve on Phe level without raising undue anxieties. One other point needs mentioning. We cannot correct for intelligence as we have no controls (only standards) and no I.Q.'s for the DM group. Within the PKU group, however, correlations between I.Q. and any of the other variables were insignificant and low. This does not preclude relations but it is improbable that all variance in our data could be explained by intelligence.

We conclude that in early-treated PKU it is particularly difficult to find constructive ways to adapt to the situation for children as well as for parents. It seems necessary to combine paediatric treatment with psychocounselling, aimed at better insight in and working through of the elaborate consequences of PKU.

Acknowledgements Data were collected by E. Lamers and G. Hoetink, students in developmental psychology, University of Amsterdam. We thank Prof. Dr. M. W. van der Molen for his advice.

\section{References}

1. Achenbach TM, Edelbrock C (1983) Manual for the child behavior check list and revised behavior profile. University of Vermont, Burlington

2. Awiszus D, Unger I (1990) Coping with PKU: results of narrative interviews with parents. Eur J Pediatr 149 [Suppl 1]: 45-51

3. Block JH, Block J (1980) The role of ego-control and ego-resilience in the organization of behavior. In: WA Collins (Ed) The Minnesota Symposia on Child Psychology 13: 39-101

4. Dekovic M (1989) Measuring dimensions and patterns of childrearing: dutch version of the block child rearing practices report (CRPR). Catholic University Nijmegen

5. Fishler K, Azen CG, Henderson R, Friedman EG, Koch R (1987) Psychoedu- cational findings among children treated for phenylketonuria. Am J Ment Defic 92: 65-73

6. Huisman J, Schot LWA van der, Hendrikx MMT, Kalverboer AF, Slijper FME (1992) The interlectual development of patients with phenylketonuria; 15 years screening in the Netherlands (in Dutch). Ned Tijdschr Geneeskd 136, 46: 2277-2281

7. Kagan J, Rosman BL, Day D, Albert J, Philips W (1964) Information processing in the child: Significance of analytic and reflective attitudes. Psychol Monogr; 78
8. Koch R, Azen C, Friedman EG, Williamson ML (1984) Paired comparisons between early-treated PKU children and their matched sibling controls on intelligence and school achievement test results at eight years of age. J Inherited Metab Dis 7: 86-90

9. Koff E, Boyle P, Sigfried M, Pueschel SM (1977) Perceptual-motor functioning in children with phenylketonuria. Am J Dis Child 131: 1084-1087

10. Luteijn F, Dijk $H$ van, Ploeg FAE van der (1989) of the Dutch personality questionnaire for children (in Dutch). Swets and Zeitlinger, Lisse, the Netherlands

11. Primrose DA (1983) Phenylketonuria with normal intelligence. J Ment Defic Res 27: 239-246

12. Realmuto GM, Garfinkel BD, Tuchman M, Tsai MY, Chang PN, Fisch RO, Shapiro S (1986) Psychiatric diag nosis and behavioral characteristics of phenylketonuric children. J Nerv Ment Dis 174(9): 536-540

13. Shulman S, Fisch RO, Zempel CE, Gadish O, Chang PN (1991) Children with phenylketonuria: the interface of family and child functioning. Dev Behav Pediatr 12(5): 315--321

14. Smith I, Beasley MG, Wolff $\mathrm{OH}$, Ades AE (1988) Behavior disturbance in 8 year old children with early treated phenylketonuria. J Pediatr 112(3): 403-408
15. Sonneville LMJ de, Schmidt E, Michel U, Batzler U (1990) Preliminary neuropsychological test results. Eur J Pediatr 149: S39-44

16. Stevenson JE, Hawcroft $\mathrm{J}$, Lobascher M, Smith I, Wolff O, Graham PJ (1979) Behavioral deviance in children with early treated phenylketonu- ria. Arch Dis Child 54: 14-18

17. Taylor EA (1986) The overactive child. Clinics in developmental medicine 97. Blackwell, Oxford

18. Verhulst FC, Akkerhuis GW, Althaus M (1985) Mental health in Dutch children: (I) a cross-cultural comparison. Acta Psychiatr Scand 72 [Suppl 323]

19. Waisbren SE, Mahon BE, Schnell RR, Levy HL (1987) Predictors of intelligence quotient and intelligence quotient change in persons treated for phenylketonuria early in life. Pediatrics 79(3): 351-355

20. Welsh MC, Pennington BF, Ozonoff S, Rouse B, McCabe ERB (1990) Neuropsychology of early-treated phenylketonuria: specific executive function deficits. Child Dev 61: 1697-1713

21. Wit CAM de (1987) Depression questionnaire for children (in Dutch) (DVK). Acco, Amersfoort 